\title{
ROLE OF PROBIOTICS IN GASTROINTESTINAL TRACT DISEASES: INFLAMMATORY BOWEL DISEASE AND NECROTIZING ENTEROCOLITIS
}

\author{
SHATAKSHI SHUKLA ${ }^{*}$, SALONI VERMA ${ }^{1}$, REKHA SHARMA ${ }^{1}$, ANKITA KUMARI ${ }^{1}$, RAHUL ADLINGE ${ }^{1}$ \\ Department of Bioengineering and Biosciences, Lovely Professional University, Phagwara, Punjab, India \\ Email: shatakshirajeshshukla@gmail.com
}

Received: 15 Sep 2020, Revised and Accepted: 17 Nov 2020

\begin{abstract}
Bacterial microflora which is present in gastrointestinal tract cause various disorders. Probiotics provides beneficial effects in gut related disease. Previously probiotics are used as alternative medicine but now entering in mainstream medicine. Probiotics help in restoring normal bacterial microflora and regulate the gastrointestinal tract functioning through different mechanisms. There are only few evidences available which show potential benefits of probiotics. The efficiency of probiotics used as a single strain or multiple formulation is tested in various diseases such oral health, diabetes, multiple sclerosis, inflammatory bowel disease, necrotising enterocolitis and many more. The purpose of this paper is to focus on diseases related to gastrointestinal tract including inflammatory bowel disease and necrotising enterocolitis based on the literature review available and propose future perspective to reduce the translocation of bacterial microflora in gastrointestinal tract and reducing subsequent inflammation of gut. Keywords were searched in goggle scholar, academic research, PubMed and Embase databases.
\end{abstract}

Keywords: Inflammatory Bowel Diseases, Necrotizing Enterocolitis, Gastrointestinal tract

(C) 2021 The Authors. Published by Innovare Academic Sciences Pvt Ltd. This is an open access article under the CC BY license (https://creativecommons.org/licenses/by/4.0/) DOI: https://dx.doi.org/10.22159/ijcpr.2021v13i1.40813. Journal homepage: https://innovareacademics.in/journals/index.php/ijcpr

\section{INTRODUCTION}

In October 2002, probiotics was defined by World Health Organisation as "live microorganisms which when administered in adequate amounts confer a health benefit on the host."With the advancement in technology various strains of probiotics mainly, lactic acid bacteria such as lactobacillus, bifidobacterium and other probiotics used in the treatment of various diseases are of significant importance. The intestinal microflora contains a wide variety of good bacteria such as lactobacillus, enterococcus, lactococcus, bifidobacterium and other bacteria which not only helps in improving digestion but also produces complex molecules such as vitamins and antibodies which enhances the immune response of the body. The selection criteria of probiotics obtained from human source are mostly preferred over plant sources, as chances of acceptance increases in case of human sources and also they possess the ability to bind or attach to the intestinal wall, providing resistance to acid and bile present in stomach. The main strains of lactic acid bacteria which are present in probiotics are lactobacillus acidophilus and bifidobacterium bifidum. (Saggioro, 2004). Probiotics shows promising effects in curing inflammatory bowel disease and preventing necrotising enterocolitis.

\section{Inflammatory bowel disease (IBD)}

The unusual action in intestine may result from the interplay between some environmental factors and the genetic susceptibility which contributes in the Inflammatory Bowel Disease. The abnormal interaction between aberrant micro flora and intestinal mucosal immune system within the intestinal tract which majorly leads to change immunological functions and triggers the inflammatory response of Inflammatory Bowel Disease [1]

Inflammatory Bowel Disease is a chronic disease of the alimentary canal that clinically contains colitis, Crohn's disease and some more symptoms. Inflammations in intestine (mucosal) of IBD can be specified by weight loss, diarrhoea, abdominal pain, bloody stools and thus the incursion of macrophages and neutrophils which have the ability to fabricate proteolytic enzyme, cytokines and free radicals results in ulceration and inflammation [2].

Crohn's disease generally contains the cecum, terminal ileum, colon and perineal area, but they may influence any part of the gut during their intermittent form. While colitis involves into the rectum and it can influence the surroundings of the Colon or the entire colon. Crohn's disease revealed histological thickening of sub mucosa, fissuring ulceration, transmural inflammation and granulomas while the mucosa and sub mucosa are restricted by inflammation of colitis with crypt abscesses and cryptitis [2].

Mechanism of action of probiotics in inflammatory bowel disease

Tolerance of probiotics to pro-inflammatory stimulus in the gastrointestinal tract

Chemokines, cytokines are overproduced by immune cells when a person is suffering from Inflammatory Bowel Disease (IBD) which acts on the epithelial cells of gastrointestinal tract such as TNF- $\alpha$ (Tumor Necrosis Factor- $\alpha$ ) which will cause epithelial cells to secrete IL 8 (Interleukin 8) which cause the overexpression of TLR 4 (Toll Like Receptor). TLR 4 is hyper-reactive in presence of LPS (Lipopolysaccharides). IL 8 and TNF- $\alpha$ is extensively express in response to foreign pathogen. Interaction between specific probiotic strains such as bifidobacterium cause the inactivation of inflammatory effector molecules provoked by pro-inflammatory stimulus. The role of probiotic strain is to act as immunosuppressive agent to inhibit $\mathrm{kB} /$ nuclear factor pathway by blocking IkB- $\alpha$ (Inhibitor kappaB-alpha) which will in turn inhibit translocation of active NF-kB (NF-kappaB) in the nucleus and supress the expression of that gene [24-26].

Role of PepT1 in promotion of colonocyte to increase defence mechanism

In epithelial cells of colon, MDP (Muramyl dipeptide) is drawn by hPepT1 (Intestinal apical di-/tripeptide transporter) which in turn activates the production of NF-kB and chemokines. Thus it is significant that PepT1 help in the promotion of colonocyte in defence mechanism of host by up taking MDP. Evidences had proven that Lactobacillus casei alter the function of PepT1 which leads to increase production of hPepT1 (3H) Gly-Sar uptake when incubated with Caco-2 cells which in turn increase the activity of PepT1 $[27,28]$. 
Table 1: Crohn disease using various probiotics

\begin{tabular}{llll}
\hline Strain & No. of patients & Outcomes & Reference \\
\hline L. Rhamnosus & 4 Children & Intestinal Permeability increased & Gupta et al., 2000 [3] \\
Saccharomyces Boulardii & 32 adults & Remission maintenance was found good & Guslandi et al., 2000 [4] \\
L. Rhamnosus & 45 adults & Endoscopic recurrence was not prevented & Prantera C et al., 2002 [5] \\
L. Rhamnosus & 11 adults & No benefit of remission maintenance & Bousvaros et al., 2005 [6] \\
L. Rhamnosus & 75 children & No time prolongation & Marteau et al., 2006 [7] \\
L. Johnsonii & 98 adults & Endoscopic recurrence was not prevented \\
L. Johnsonii & 70 adults & Endoscopic recurrence was not prevented & Van Gossum et, 2007 [8] \\
Saccharomyces Boulardii & 165 adults & No benefit of remission maintenance & Bourreille et al., 2013 [9] \\
\hline
\end{tabular}

Table 2: Studies on irritable bowel syndrome using various probiotics

\begin{tabular}{|c|c|c|c|}
\hline Strain & No. of patients & Outcome & Reference \\
\hline L. plantarum & 40 adults & Recovered & Niedzielin et al., 2001 [10] \\
\hline Bifidobacterium Infantis & 362 adult women & Relieve in pain & Whorwell et al., 2004 [11] \\
\hline Bifidobacterium Infantis & 77 adults & $\begin{array}{l}\text { Relieve in pain but did not show any improvement in stool } \\
\text { frequency. }\end{array}$ & O’manhony et al., 2005 [12] \\
\hline Bifidobacterium Animalis & 274 adults & Improvement in blotting & Guyonnet et al., 2007 [13] \\
\hline Bacillus Coagulans & 61 adults & Improvement in stool frequency & Dolin et al., 2009 [14] \\
\hline L. Rhamnosus & 141 children & Relieve in pain & Francavilla et al., 2010 [15] \\
\hline VSL\#3 & 59 children & Improvement in bloating but no relieve in stool frequency & Guandalini et al., 2010 [16] \\
\hline Saccharomyces Boulardii & 70 adults & No improvement seen & Kabir et al., 2011 [17] \\
\hline Bifidobacterium Bifidium & 122 adults & Overall improvement seen & Gulgliemetti et al., 2011 [18] \\
\hline Saccharomyces Boulardii & 67 adults & No improvement in stool frequency & Choi et al., 2011 [19] \\
\hline L. Rhamnosus & 80 adults & No improvement & Dapoigny et al., 2012 [20] \\
\hline VSL\#3 (Probiotic capsule) & 50 adults & $\begin{array}{l}\text { Overall improvement but benefits in particular symptoms } \\
\text { were not shown }\end{array}$ & Ki Cha et al., 2012 [21] \\
\hline L. plantarum & 214 adults & $\begin{array}{l}\text { Improvement in pain but no improvement in stool } \\
\text { frequency. }\end{array}$ & Ducrotte et al., 2012 [22] \\
\hline L. Salivarius & 131 adults & No major improvement seen & Begtrup et al., 2013 [23] \\
\hline
\end{tabular}

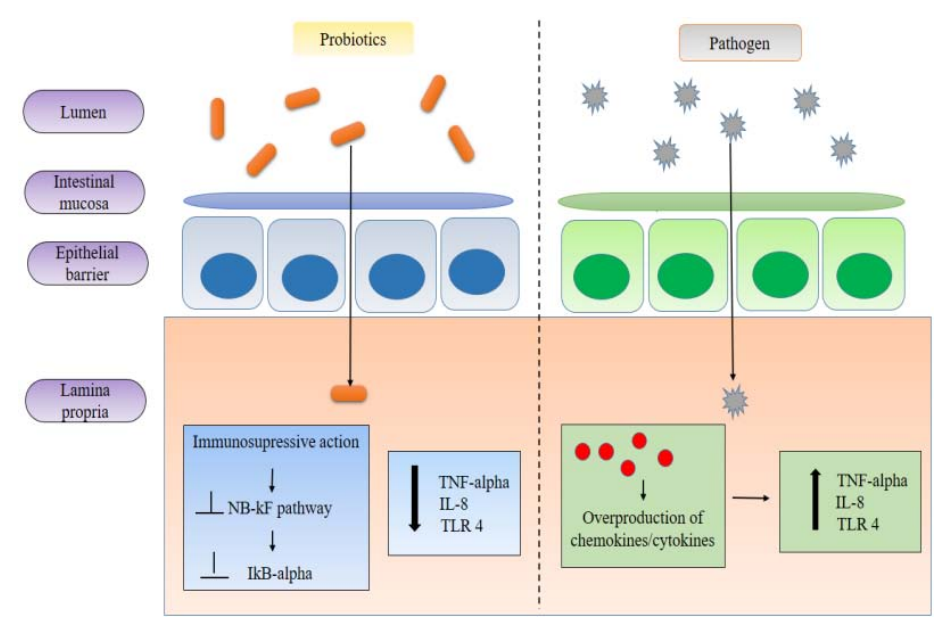

Fig. 1: Probiotics shows immunosupressive effect in intestinal epithelial barrier and mucosal immune cells by downregulating the proinflammatory cytokines. Synopsis: TNF-alpha (Tumor Necrosis Factor-alpha), IL-8 (Interleukin-8), TLR 4 (Toll like Receptor 4), NF-kB (Nuclear Factor Kappa B), IkB-alpha (Inhibitory kappa B-alpha)

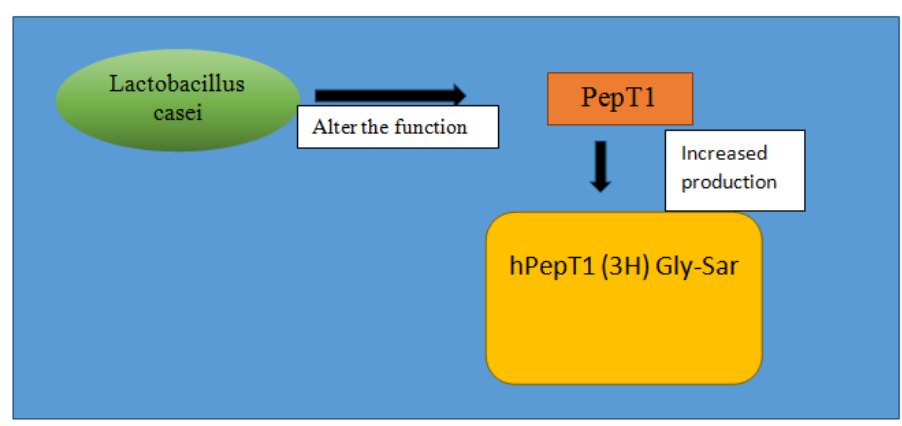

Fig. 2: Action of lactobacillus on PepT1 to increase production of hPepT1 (3H) Gly-Sar. Synopsis: PepT1 (Intestinal apical di-/tripeptide transporter) 


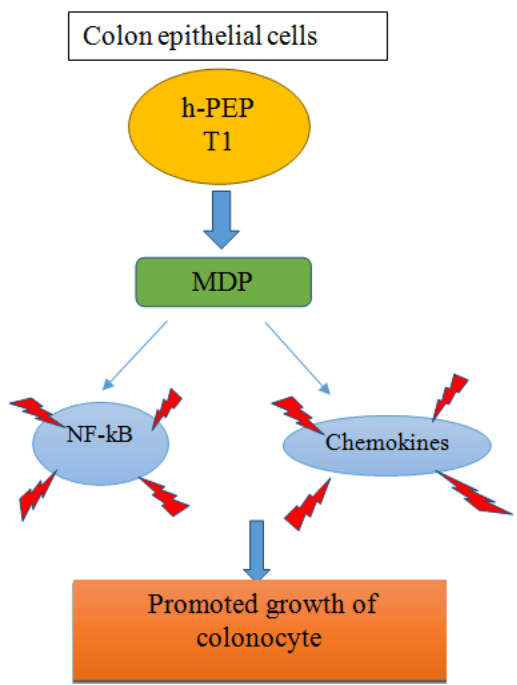

Fig. 3: Role of hPepT1 (Intestinal apical di-/tripeptide transporter) in promoting growth of colonocyte to increase defence mechanism

\section{Modification of immune response by probiotic strains}

Several studies were conducted in which mucus samples from person suffering with Crohn's disease were collected and cultured with probiotic strains such as Lactobacillus casei, L. Crispatus and L. Bulgaricus and E. coli and some samples are incubated alone. Observation shown that samples cultured with $\mathrm{L}$. casei and L. Bulgaricus had reduced number of TNF- $\alpha$ and CD4 cells expression as compared to L. Crispatus and E. coli. This signifies the interaction of probiotics with immunocompetent cells to decrease the production of pro-inflammatory chemokines and cytokines [29].

\section{Role of TLR signalling in limiting intestinal inflammation}

TLR (Toll-like receptors) act as pathogen recognition which is responsible to initiate the inflammatory immune response which will in turn help in destroying the foreign pathogens. TLR9 signalling helps in regulating the anti-inflammatory effect of probiotics. Evidences proved that peripheral blood T cells (PBT) cell cycling and apoptosis is affected by E. coli Nissle (demonstrated by Strum et al. 65). When PBT consisting of anti-CD3 factors incubated with E. coli Nissle it causes the inhibition of cell cycling of PBT, cause in downregulation of Cyclin D2, B1 and expression of retinoblastoma which play a major role in downregulation $\mathrm{T}$ cell proliferation, IL2, TNF- $\alpha$, INF- $\gamma$, and upregulation of IL10 in PBT. E. coli Nissle is responsible for inhibition of proliferation of PBT which is TLR2 dependent [30].

Modulation of inflammatory response by PPAR (proliferator activated receptor pathway)

Colitis is inhibited by PPARc pathway by deactivating the activity of NF-kB. It's increased by Bacteroides thetaiotaomicron, RelA export from the nucleus through PPARc dependent anti-inflammatory mechanism is a subunit of NF-kB. PPAR forms a complex with RelA and when $B$ thetaiotaomicron come in contact with this complex it will undergo redistribution which is cause of IBD treatment [31-33].

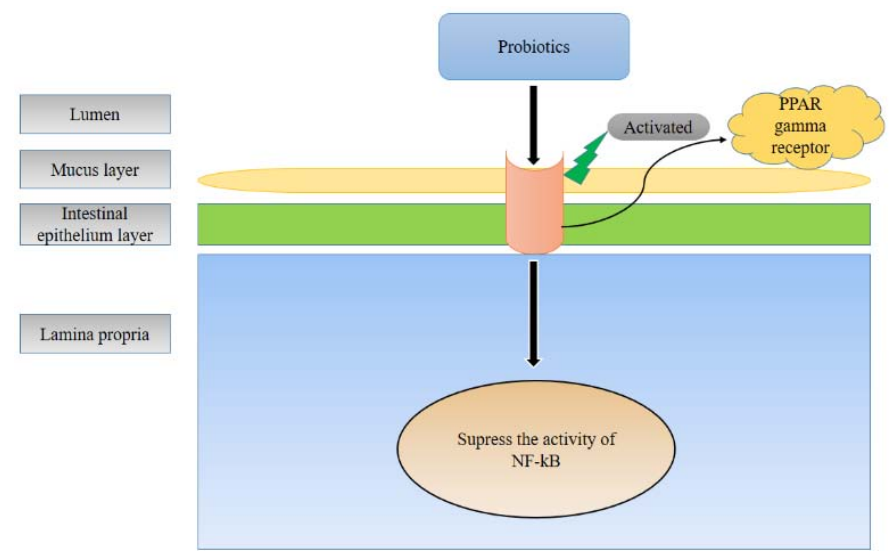

Fig. 4: Probiotic mechanism in order to modulate activation of peroxisome proliferator activated receptor (PPAR gamma) pathway. Synopsis: NF-kB (Nuclear Factor kappa B), PPAR gamma (Peroxisome proliferator activated receptor gamma)

\section{Necrotising enterocolitis}

The premature infants which are nearly less than 32-34 w, develops a devastating gastrointestinal disease named ' Necrotising Enterocolitis ' which severely effects the intestine of such infants. The term necrotising enter colitis happens when the tissues of the intestine gets ruptured. Clinical studies suggest that this disease usually affects $1 \%-5 \%$ out of $2000-4000$ infants [34]. It has been also observed that this disease is very rarely found in fully matured infants. The premature infants generally are weaker as compared to the fully matured infants, so there are more chances of them to get affected by this disease [35].

The proper validated cause of this disease is still not known but several assumptions and observations have been made which determines the reasons of premature infants being majorly affected 
by this severe disease. Instead of feeding premature infants with breast milk, they are provided with formula feeding which has been considered as the major cause of ill development of the infant in terms of immunity. The premature infants have weaker organs as compared to those of fully developed babies. Thus any decrement in oxygen supply to the organs especially in lungs and intestine can progressively result in damaging the linings of intestine. The damaged walls further help in the bacterial invasion in which the linings of the wall of the intestine is attacked by a number of bacteria which primarily causes local infection and later on causes irritable inflammation in the intestine of the infant. This invasion thus leads to the perforation of the intestinal walls and also the spillage of stool into the abdomen region of the infected infant [36].

Study related to probiotics potential against necrotising enterocolitis

The good bacteria i.e. the Probiotics have been considered from last few years as a good alternative source for helping in the reduction of necrotizing enterocolitis. Meta-analysis of some reviews shows that there is a gradual declination in the rise of stage II NEC after supplementing the patients with probiotics. Several animal models have also been studied for knowing the proper mechanism, benefits and effects of utilizing probiotics in such cases [37].

Systematic reviews of such sample studies which were conducted on a small scale gave a brighter knowledge about the use of probiotics more precisely and strongly.

Probiotics have been widely being used for trials and studies for knowing its effect on premature infants. A number of bacterial strains like of bifidobacterium and lactobacillus were extensively used for studying. These bacterial strains were considered because of their abundance in infants. It was observed in studies that the bifidobacterium was less abundant in premature infants who were feeded without breast milk. This happens because the human milk oligosaccharide is more and more consumed by bifidobacterium which results their abundance in the fully matured infants as of compared to the premature ones [38].

A cumulative study represented a report which was considered as the largest trials on probiotics in term of knowing its effect on necrotising enterocolitis. A total of 1315 infants were kept under surveillance in a PiPS trial. In this study it was noted that no harm was seen by the use of probiotics, so there were less chances of risk for the treatment [39].

Several interventions were kept under observation to know the effect of probiotic. A total of 35 trials were conducted on 10,520 patients were it was seen the difference in the condition of necrotising enterocolitis by dividing some of them with treatment of probiotics while some of them were deprived of it. The result showed mixed results [40]. So later it was described that for having a positive impact of probiotics in the prevention of necrotising enterocolitis there must be proper choices of product with keeping in mind of certain specific parameters which includes low risk factors. To give a detailed view of this a survey report in an article was conducted on for 16 different products of probiotics which was being used for this purpose in US neonatal intensive unit cares (NICU). The reports of this survey compelled the authors to declare that there was a huge dominance of the products which were having common bacterial strain preparation of Lactobacillus rhamnosus or lactobacillus reuteri of about $50 \%$ of its positive results [41].

Also, a cohort study of France revealed that there was tremendous decrease in the cases of necrotising enterocolitis after treating the infected infants with these lactobacillus strain labelled products [42].

\section{Mechanism of action of probiotics NEC in premature infant}

There are number of in vitro studies including mechanism occurring in the gut, specific to commensal bacterial strain in order to prevent NEC disease in preterm infant [43].

\section{Up-regulating the cytoprotective gene expression}

Commensal bacterial strain named as Bacteroides thetaiotaomicron regulate the mRNA expression of gene related to gastrointestinal function which included improvement in nutrient absorption capacity of the host and processing. Establishment of colonies of Bacteroides thetaiotaomicron showed the increase ileal $\mathrm{Na}$ /glucose co-transporter (SGLT-1) mRNA expression, after the administration of $\mathrm{B}$. thetaiotaomicron in the host led to the induction of immunoglobulin A (T-cell independent) producing B-cells by increasing the expression of polymeric immunoglobulin receptor (pIgR) that helps in transportation of IgA covering epithelium lining and provide coherency, increases host capacity towards metabolization of xenobiotic and endotoxin, Colonization of this bacteria up regulate the mRNA of angiogenin-3, specifically in intestinal crypt epithelium [44].

\section{Reducing the mRNA expression of pro-inflammatory molecules}

Commensal bacteria such as Lactobacillus rhamnosus GG that help in blocking of inflammatory responses produces in intestinal epithelia by generating reactive oxygen species (ROS) that responsible for inhibition of NF-kappaB through oxidative deactivation of modulate Ubc12 enzyme and TNF-alpha that was also included in switching on of NF-kappaB, ROS generation by the LGG in vitro and in vivo in intestinal epithelium layer. From the study it was suggested that Salmonella Strain (non-virulent) provide tolerance towards pro-inflammatory stimuli by blocking (Inhibitor kappaB-alpha/NF-kappaB) through the phosphorylation and polyubiquitination of IkappaB-alpha and led to its degradation [45].

\section{Synthesis of butanoate and short chain fatty acids metabolites}

Synthesised metabolite helps in nourishment of epithelial cells of colon and decreases the $\mathrm{pH}$ and oxygen stress in intestinal lumen which led to the retardation of growth of bacteria e. g. clostridia and enterobacteria, it also decreases the intestinal inflammatory calprotectin and increases IgA. Number of studies support probiotic bacterial strain that improved the integrity of intestinal epithelial barrier by restricted the diffusion of small solutes, macro-molecules and endogenous toxins and regulate the expression of intestinal mucosa related factor which are involved in modulation and maintenance, which include TLR4 (Toll-like Receptors 4), TLR9, mucin and trefoil factor (TFF) and antimicrobial polypeptide molecules [46].

\section{Maturation of intestinal barrier and its proper functioning}

Previous report show that commensal bacteria mainly LGG colonization in intestinal region promote intestinal barrier coherency and its maturation by inducing the mRNA level of claudin 3 by introduction of LGG either live or non-live formulation as probiotics. Study based on MyD88-/-mice show that TLR2 perform essential role in tight junction protein (TJ protein) expression and promote maturation of intestinal barrier through TLR signalling pathway. As seen in premature infant affected with NEC, study related to this suggested that claudin 3 ubiquitous TJ protein transcriptionally upregulated during the phase of postnatal growth [47].

\section{Regulate immune response through stimulation of dendritic} cells

Probiotics helping in activation of T-cell activation and their balancing of Th1:Th2. Two commensal bacteria in order to treat clinical NEC named as L. lactis and B. infantum able to alter mRNA level of gene responsible for innate immunity and at same instance decreases the IL-8 expression. Commensal bacteria perform a crucial function in balancing of T-helper cells. In intestinal region, undeveloped dendritic cqawd ells (DCs) localised in the lamina propria extend the appendages in between enterocytes goes into intestinal lumen. These appendages expose TLR-2,4 through these receptors commensal bacteria interact, immature DCs cell converted into mature DCs that provide the surrounding favourable for maturation and balance of Th1 and Th2 cells [48]. 


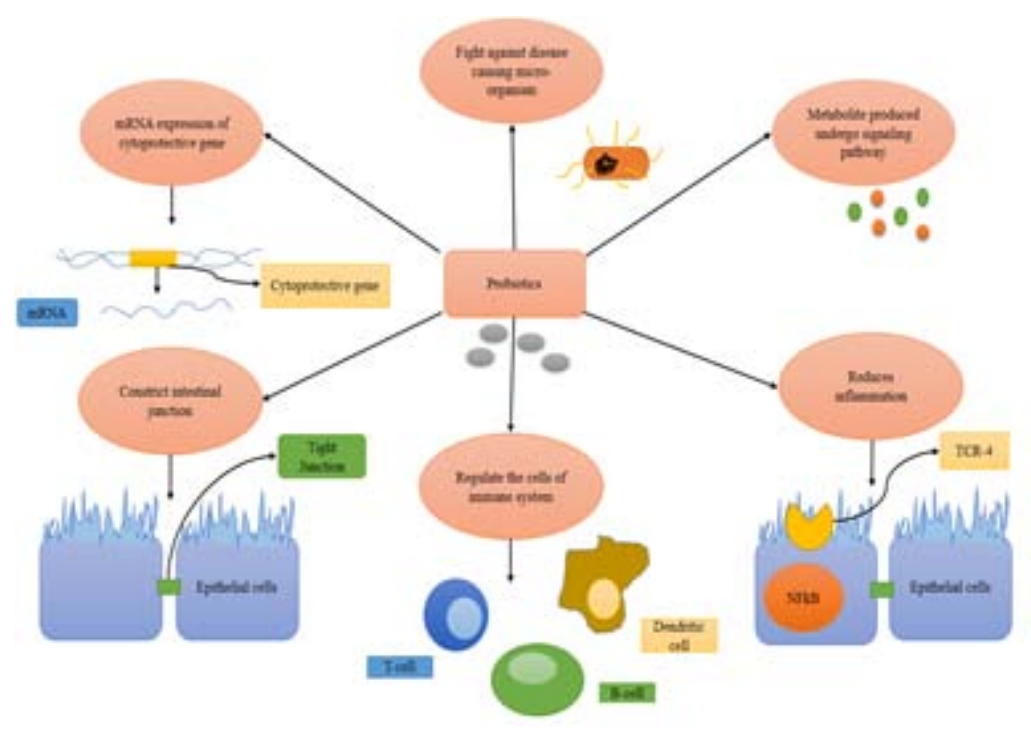

Fig. 2: This fig. shows number of mechanism that probiotic undergo to prevent NEC in premature new born and improve the gastrointestinal immaturity. Synopsis: TLR4 (Toll-like receptor 4), NFkB (Nuclear Factor Kappa B)

\section{CONCLUSION}

Probiotics serves a potential source for treatment of various diseases. Studies which were conducted on Mice, rats or other animal models given us positive results which states that probiotics has prominent effect on treatment of various diseases related to gastrointestinal tract. Along with this one major advantage of probiotics is that, they do not possess any significant side effects. They play an important role in decreasing the time duration of infection in the body and its susceptibility.

The major evidence is that probiotics are strain specific that means specific strain is responsible for treating specific disease. In case of inflammatory bowel disease, lactobacillus plantarum, lactobacillus bifidobacterium and lactobacillus rhamnosus shown prominent effect for its treatment. Moreover, the working mechanism of every probiotics and health conditions caused by them are different in each case.

In case of necrotizing enterocolitis, studies of Meta analyses have shown decrease in NEC Stage 2, when administered with probiotics. Many studies across the world have proven evidence of success when administered with prophylactic probiotics. In this review, different mechanism of working of different probiotics in case of NEC and their therapeutic efficiency has proven. Cluster randomized clinical trials comparing commercially available probiotic strains sufficiently determine the difference on NEC. Researches have proven potential side effects possess by nutritional supplements and hence banned them. There is a wide scope of probiotics to be one of the finest therapy to treat various gastrointestinal disease. Moreover, the focus of study is shifted to properties, functions and composition of probiotics.

\section{FUNDING}

Nil

\section{AUTHORS CONTRIBUTIONS}

All the authors have contributed equally.

\section{CONFLICT OF INTERESTS}

Declared none

\section{REFERENCES}

1. AP Bai, Q Ouyang. Probiotics and inflammatory bowel diseases. Postgrad Med J 2006;82:376-82.

2. Qingdong Guan. A comprehensive review and update on the pathogenesis of inflammatory bowel disease. J Immunol Res 2019;16:7247238.
3. Schultz M, Timmer A, Herfarth HH, Sartor RB, Vanderhoof JA, Rath HC. Lactobacillus GG in inducing and maintaining remission of Crohn's disease. BMC Gastroenterol 2004;4:5.

4. Bousvaros A, Guandalini S, Baldassano RN, Botelho C, Evans J, Ferry $\mathrm{GD}$, et al. A randomized, double-blind trial of lactobacillus GG versus placebo in addition to standard maintenance therapy for children with Crohn's disease. Inflamm Bowel Dis 2005;11:833-9.

5. Guslandi M, Mezzi G, Sorghi M, Testoni PA. Saccharomyces boulardii in maintenance treatment of Crohn's disease. Dig Dis Sci 2000;45:1462-4.

6. Bourreille A, Cadiot G, Le Dreau G, Laharie D, Beaugerie L, Dupas JL, et al. Saccharomyces boulardii does not prevent relapse of Crohn's disease. Clin Gastroenterol Hepatol 2013;11:982-7.

7. Malchow HA. Crohn's disease and Escherichia coli. A new approach in therapy to maintain remission of colonic Crohn's disease? J Clin Gastroenterol 1997;25:653-8.

8. Van Gossum A, Dewit O, Louis E, de Hertogh G, Baert F, Fontaine $\mathrm{F}$, et al. Multicenter randomizedcontrolled clinical trial of probiotics (Lactobacillus johnsonii, LA1) on early endoscopic recurrence of Crohn's disease after lleo-caecal resection. Inflamm Bowel Dis 2007;13:135-42.

9. Prantera C, Scribano ML, Falasco G, Andreoli A, Luzi C. Ineffectiveness of probiotics in preventing recurrence after curative resection for Crohn's disease: a randomised controlled trial with Lactobacillus GG. Gut 2002;51:405-9.

10. Marteau P, Lemann M, Seksik P, Laharie D, Colombel JF, Bouhnik Y, et al. Ineffectiveness of lactobacillus johnsonii LA1 for prophylaxis of postoperative recurrence in Crohn's disease: a randomised, double blind, placebo controlled GETAID trial. Gut 2006;55:842-7.

11. Simren M, Ohman L, Olsson J, Svensson U, Ohlson K, Posserud I, et al. Clinical trial: the effects of a fermented milk containing three probiotic bacteria in patients with irritable bowel syndrome-a randomized, double-blind, controlled study. Aliment Pharmacol Ther 2010;31:218-27.

12. Begtrup LM, de Muckadell OB, Kjeldsen J, Christensen RD, Jarbøl DE. Long-term treatment with probiotics in primary care patients with irritable bowel syndrome--a randomised, double-blind, placebo controlled trial. Scand J Gastroenterol 2013;48:1127-35.

13. Sondergaard B, Olsson J, Ohlson K, Svensson U, Bytzer P, Ekesbo R. Effects of probiotic fermented milk on symptoms and intestinal flora in patients with irritable bowel syndrome: a randomized, placebocontrolled trial. Scand J Gastroenterol 2011;46:663-72.

14. O'Mahony L, McCarthy J, Kelly P, Hurley G, Luo F, Chen K, et al. Lactobacillus and bifidobacterium in irritable bowel syndrome: symptom responses and relationship to cytokine profiles. Gastroenterology 2005;128:541-51. 
15. Gawronska A, Dziechciarz P, Horvath A, Szajewska H. A randomized double-blind placebo-controlled trial of lactobacillus GG for abdominal pain disorders in children. Aliment Pharmacol Ther 2007;25:177-84.

16. Dapoigny $M$, Piche $T$, Ducrotte $P$, Lunaud $B$, Cardot JM, Bernalier Donadille A. Efficacy and safety profile of LCR35 complete freeze-dried culture in irritable bowel syndrome: a randomized, double-blind study. World J Gastroenterol 2012;18:2067-75.

17. Ki Cha B, Mun Jung S, Hwan Choi C, Song ID, Woong Lee H, Joon Kim $\mathrm{H}$, et al. The effect of a multispecies probiotic mixture on the symptoms and fecal microbiota in diarrhea-dominant irritable bowel syndrome: a randomized, double-blind, placebo-controlled trial. J Clin Gastroenterol 2012;46:220-7.

18. Kabir MA, Ishaque SM, Ali MS, Mahmuduzzaman M, Hasan M. Role of Saccharomyces boulardii in diarrhea predominant irritable bowel syndrome. Mymensingh Med J 2011;20:397-401.

19. Choi CH, Jo SY, Park HJ, Chang SK, Byeon JS, Myung SJ. A randomized, double-blind, placebo-controlled multicenter trial of saccharomyces boulardii in irritable bowel syndrome: effect on quality of life. J Clin Gastroenterol 2011;45:679-83.

20. Dolin BJ. Effects of a proprietary bacillus coagulans preparation on symptoms of diarrhea-predominant irritable bowel syndrome. Methods Find Exp Clin Pharmacol 2009;31:655-9.

21. Shin MS, Han SK, Ji AR, Kim KS, Lee WK. Isolation and characterization of bacteriocin-producing bacteria from the gastrointestinal tract of broiler chickens for probiotic use. J Appl Microbiol 2008;105:2203-12.

22. Petricevic L, Witt A. The role of lactobacillus casei rhamnosus Lcr35 in restoring the normal vaginal flora after antibiotic treatment of bacterial vaginosis. BJOG 2008;115:1369-74.

23. Van Gossum A, Dewit O, Louis E, de Hertogh G, Baert F, Fontaine $\mathrm{F}$, et al. Multicenter randomized-controlled clinical trial of probiotics (Lactobacillus johnsonii, LA1) on early endoscopic recurrence of Crohn's disease after lleocaecal resection. Inflamm Bowel Dis 2007;13:135-42.

24. Eckmann L, Jung HC, Schurer Maly C. Differential cytokine expression by human intestinal epithelial cell lines: regulated expression of interleukin 8. Gastroenterology 1993;105:1689-97.

25. Neish AS, Gewirtz AT, Zeng H. Prokaryotic regulation of epithelial responses by inhibition of IkappaB-alpha ubiquitination. Science 2000;289:1560-3.

26. Vavricka SR, Musch MW, Chang JE. hPepT1 transports muramyl dipeptide, activating NF-kappaB and stimulating IL-8 secretion in human colonic Caco2/bbe cells. Gastroenterology 2004;127:1401-9.

27. Neudeck BL, Loeb JM, Faith NG. Lactobacillus casei alters hPEPT1-mediated glycylsarcosine uptake in caco-2 cells. J Nutr 2004;134:1120-3.

28. Borruel N, Carol M, Casellas F. Increased mucosal tumour necrosis factor alpha production in Crohn's disease can be downregulated ex vivo by probiotic bacteria. Gut 2002;51:659-64.

29. Andreakos E, Foxwell B, Feldmann M. Is targeting toll-like receptors and their signaling pathway a useful therapeutic approach to modulating cytokinedriven inflammation? Immunol Rev 2004;202:250-65.

30. Nencioni A, Wesselborg S, Brossart P. Role of peroxisome proliferatoractivated receptor gamma and its ligands in the control of immune responses. Crit Rev Immunol 2003;23:1-13.
31. Dubuquoy L, Jansson EA, Deeb S. Impaired expression of peroxisome proliferator-activated receptor gamma in ulcerative colitis. Gastroenterology 2003;124:1265-76.

32. Kelly D, Campbell JI, King TP. Commensal anaerobic gut bacteria attenuate inflammation by regulating nuclearcytoplasmic shuttling of PPARgamma and RelA. Nat Immunol 2004;5:104-12.

33. Kim SH, Yang SJ, Koo HC. Inhibitory activity of Bifidobacterium longum HY8001 against vero cytotoxin of escherichia coli 0157:H7. J Food Prot 2001;64:1667-73.

34. Martin RJ, Fanaroff AA, Walsh MC. eds. Caplan M. Neonatal necrotizing enterocolitis. In: Fanaroff and Martin's NeonatalPerinatal Medicine. $10^{\text {th }}$ ed. Philadelphia, PA: Elsevier Saunders; 2015. p. 94.

35. Greenberg JM, Haberman B, Narendran V, Nathan AT, Schibler K. Neonatal morbidities of prenatal origin. In: Resnik R, Lockwood CJ, Moore TR, Greene MF, Copel JA, Silver RM. eds. Creasy and Resnik's Maternal-Fetal Medicine: Principles and Practice. 8th ed. Philadelphia, PA: Elsevier; 2019. p. 73.

36. Kliegman RM, St Geme JW, Blum NJ, Shah SS, Tasker RC, Wilson $\mathrm{KM}$, eds. Seed PC. The microbiome and pediatric health. In: Nelson Textbook of Pediatrics. 21 $1^{\text {st }}$ ed. Philadelphia, PA: Elsevier; 2020. p. 196.

37. Sawh SC, Deshpande S, Jansen S, Reynaert CJ, Jones PM PeerJ. Prevention of necrotizing enterocolitis with probiotics: a systematic review and meta-analysis. 2016;4:e2429.

38. Garrison D, Barile D, Mills DA. A molecular basis for bifidobacterial enrichment in the infant gastrointestinal tract. Adv Nutr 2012;3:415S-21S.

39. Costeloe K, Hardy P, Juszczak E, Wilks M, Millar MR. Probiotics in preterm infants study collaborative group. Bifidobacterium breve BBG-001 in very preterm infants: a randomised controlled phase 3 trial. Lancet 2016;387:649-60.

40. Dani C, Coviello CC, Corsini II, Arena F, Antonelli A, Rossolini GM. Lactobacillus sepsis and probiotic therapy in newborns: two new cases and literature review. AJP Rep 2016;6:e25-9.

41. US Food and Drug Administration. FDA Investigates Presence of Mucormycosis-causing Mold in Infant and Children's Probiotic Supplement; 2016.

42. Underwood MA. Impact of probiotics on necrotizing enterocolitis. Semin Perinatol 2017;41:41-51.

43. Hooper LV, Wong MH, Thelin A, Hansson L, Falk PG, Gordon JI. Molecular analysis of commensal host-microbial relationships in the intestine. Science 2001;291:881-4.

44. Lin PW, Myers LE, Ray L, Song SC, Nasr TR, Berardinelli AJ, et al. Lactobacillus rhamnosus blocks inflammatory signaling in vivo via reactive oxygen species generation. Free Radical Biol Med 2009;47:1205-11.

45. Neish AS, Gewirtz AT, Zeng H, Young AN, Hobert ME, Karmali V, et al. Prokaryotic regulation of epithelial responses by inhibition of IkappaB-alpha ubiquitination. Science 2000;289:1560-3.

46. Rivera Chavez F, Lopez CA, Baumler AJ. Oxygen as a driver of gut dysbiosis. Free Radical Biol Med 2017;105:93-101.

47. Patel RM, Myers LS, Kurundkar AR, Maheshwari A, Nusrat A, Lin PW. Probiotic bacteria induce maturation of intestinal claudin 3 expression and barrier function. Am J Pathol 2012;180:626-35.

48. Walker WA. Mechanisms of action of probiotics. Clin Infect Dis 2008;46(Suppl 2):S87-91, S144-51. 